\title{
How to survive diabetes
}

\section{E. A. M. Gale}

Published online: 7 February 2009

(C) Springer-Verlag 2009

\section{I prefer old age to the alternative.}

Maurice Chevalier

\section{Cold Comfort Farm}

Raymond is a lean and weather-beaten 75 -year-old, with the slow movements and deliberate conversation of a man who has spent his life among cows. He was in his work clothes when I visited the farm, and the pale scar left by an aortic valve replacement showed beneath his shirt. His exercise stress test had been normal, however, and I struggled to keep up as we headed across the pasture to inspect his beloved dairy herd. Raymond developed diabetes 58 years ago. The surgeons found healthy coronary arteries when they did his valve replacement in 2004, and he has no proteinuria or retinopathy. Like all farmers, he complains of his back. As we walked among the herd and he instructed me in the finer points of bovine anatomy, I thought of all the young people who developed diabetes in 1950 and are now in their graves. We stooped to examine a mysterious swelling on one of the animals, but I could only wonder: Why you?

\section{Great Expectations}

Children starting insulin today might reasonably wish for a near-normal life, a near-normal lifespan and freedom from diabetes-related concerns. Although the chances of success have never been better, this wish will be denied to many

\section{E. A. M. Gale $(\bowtie)$}

Diabetes and Metabolism, Medical School Unit,

Southmead Hospital,

Bristol BS10 5NB, UK

e-mail: Edwin.Gale@bristol.ac.uk
[1]. Elliott Joslin expressed much the same hope in a mission statement he wrote when insulin became available in 1923. Children with diabetes, as this proclaimed, should henceforth be treated in the expectation of a long and healthy life. Suitably modified, his Diabetic Creed-as he chose to call it - appeared in each succeeding edition of his textbook, fleshed out by the slow accumulation of survival statistics. The 1940 edition estimated 40 additional years for a 10-year-old with newly diagnosed diabetes, as against 57 for a non-diabetic child of the same age, and-optimistic as ever-his Creed now stated that a child on insulin should expect at least 50 more years of life [2].

\section{Hard Times}

Sadly, this was too optimistic. Retrospective analysis showed that those diagnosed before the age of 30 who attended his clinic from 1923-1945 died at a median age of 44 years [3]. Joslin himself said that 'children with diabetes now live so long that we are forced to depend upon their calculated life expectancy' [2]. This is what led him astray, for he extrapolated from the first 20 years of insulin therapy, when mortality is relatively low, to the next 20 years, when it takes a dive. Louis Dublin, a contemporary life insurance expert, made the same mistake [4] (Fig. 1). Joslin was, however, quite right to say that the prognosis of childhood diabetes would improve. Analysis of those who attended his clinic from 1923-1959 later showed that $52 \%$ of women and $46 \%$ of men diagnosed at age 10 would see their 50th birthday, in excellent accord with his 40 year survival estimate in 1940. On a less positive note, $93 \%$ of girls and $91 \%$ of boys aged 10 in the background population would also reach the age of 50 , which meant that a diagnosis of childhood diabetes equated to the loss of 25 years of life [3]. By 1959, a girl diagnosed at age 10 had a $71 \%$ chance of reaching the age of 50 , as against $65 \%$ for a boy, and their projected median lifespan 


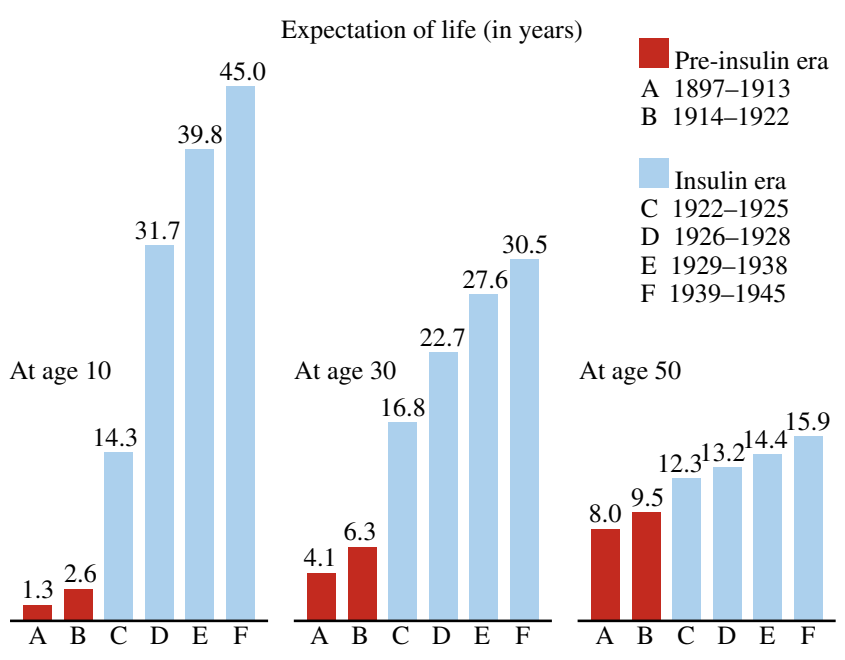

Fig. 1 Survival of people with diabetes by age and date of diagnosis. The survival of young insulin-treated patients was overestimated, as explained in the text. Redrawn from [4]

had risen to 55-60 years of age, still 20 years less than might otherwise be expected [5].

\section{Looking Backward}

Each medical solution generates its own problems, and the great gift of insulin created a fearful legacy of delayed complications. Like Joslin, we have high hopes for the present generation but, like him, we are only equipped with a rear-view mirror. His experience should remind us that it is not always easy to judge the future from the past. Cohort studies from the Joslin Clinic and the Steno Memorial Hospital provide the best retrospective information we have, but the treatment and natural history of diabetes have changed so rapidly that the fate of those diagnosed 50 years ago may have limited relevance to the challenges we face today. We should not forget that the prognosis of the background population also improved - at the astonishing rate of 3-4 months of extra life for each calendar yearover much of the 20th century. Children with diabetes should be living 20 years longer, regardless of any changes we have made in their therapy.

Current mortality rates could, in theory, be assessed from death certificates but, as J. B. S. Haldane once commented about newspapers, the only piece of information these contain that you can really trust is the date. In all events, the certificates often fail to mention diabetes. Their real value emerges in relation to prospective cohort studies, and prospective studies are as close as we can get to a realtime estimate of the prognosis of diabetes. As we shall see, both clinic- and population-based studies offer reassurance [1], but the clinic-based studies are more reassuring than the epidemiological ones, and few cover more than 30 years. Joslin's error was to infer the second 20 years of diabetes from the first, and we have yet to ascertain the extent to which the renal and cardiac complications of diabetes have been abolished or merely postponed by modern management. Nonetheless, an increasing number of children with diabetes will enjoy 50 additional years of life, and we can learn something about their future from those who have already managed to do so.

\section{Look! We Have Come Through!}

Although some of Joslin's contemporaries concluded that the vascular complications of diabetes were inevitable, others could demonstrate that childhood diabetes is compatible with long and healthy survival. Hagedorn reported that five of the first eight Danish patients to be treated with insulin (prepared in his own kitchen) were still alive 26 years later, and that four had no proteinuria or significant retinopathy [6]. Joslin's medals for long survival provide useful landmarks on the road to increasing longevity. The first, inscribed 'Explorers of unknown seas', was awarded after 10 years of diabetes [1], increasing to 25 years with the Quarter Century Victory Medal in 1948; winners of the latter must be certified free from retinopathy, proteinuria, hypertension and vascular calcification [7]. The name of the Victory Medal was soon changed to the more neutral 'Blue Ribbon' [8], perhaps to avoid the triumphalist overtones of the earlier name. The 50 year medal followed in 1970, which was awarded regardless of complications; 246 Americans had won this by 1979 [9], and there are currently more than 2,400 winners worldwide [8]. The British equivalent has been won by more than 800 individuals, and additional medals for 60 and 70 year survival are now awarded on both sides of the Atlantic.

Studies of long-term survivors reveal some consistent features [10-14]. For example, a clinical survey of 92 individuals who had survived for more than 40 years found that 30 had no detectable complications, 22 had 'minor' complications (mainly background retinopathy), 16 were blind or visually impaired, two had disabling neuropathy and eight had proteinuria. As a group, the survivors were lean $(92 \%$ of expected body weight) and normotensive [10].

A study from the Steno Memorial Hospital found that $42 \%$ of 906 insulin-dependent patients diagnosed before 1943 , all of whom presented under the age of 31 and were seen at the hospital within 10 years of first diagnosis, survived for 40 years or more, and that half of these $(20 \%$ of the total) did so without major complications of diabetes. The study is of particular interest because it compared the characteristics of all those meeting the entry criteria who 
died within 35 years of diagnosis with those of 40 year survivors. Age at onset, BMI, blood pressure and insulin dose were identical in the two groups. More men died than women, but not when corrected for relative mortality [11, 12]. The more recent UK Golden Years study reports data collected by research nurses in the course of home visits, and provides indirect testimony as to the impact of laser therapy, for of the 40050 year medalists, only $2 \%$ were blind [13]. The Joslin Medalist study reported questionnaire data on 326 similar individuals [14], and the two studies are compared in Table 1.

\section{Survivors, Delayers and Escapers}

One person in 10,000 lives to be 100 , and few survivor groups have attracted more attention than centenarians, who are oddly similar to the long-term veterans of diabetes. Centenarians are said to fall into three groups: survivors, delayers and escapers [15], and the same categories can be applied to 50 year medal winners. Survivors of diabetes reach 50 years despite overt complications, delayers have subclinical complications such as retinopathy and/or renal disease, and escapers have no detectable complications at all. Survivors predominate. In Golden Years, for example,

Table 1 Characteristics of participants in the UK Golden Years and Joslin Medalist studies

\begin{tabular}{lll}
\hline Variable & Golden Years study & $\begin{array}{l}\text { Medalist } \\
\text { study }\end{array}$ \\
\hline $\begin{array}{l}\text { Number studied (total } \\
\text { available) }\end{array}$ & $400(581)$ & $326(501)$ \\
Male (\%) & 54 & 45.3 \\
Age at diagnosis (years) & 13.7 & 12.6 \\
Age at study (years) & 68.9 & 69.5 \\
BMI (kg/m ${ }^{2}$ ) & 25.0 & 24.5 \\
Insulin dose (U/kg) & 0.52 & 0.50 \\
HbA ${ }_{1 \mathrm{c}}(\%)^{\mathrm{a}}$ & 7.6 (not DCCT & 7.0 \\
& aligned) & \\
HDL-cholesterol (mmol/l) & 1.84 & 1.75 \\
Parental age at death, M/F & $71 / 71$ & $73.6 / 78.4$ \\
$\quad$ (years) & & - \\
Microalbuminuria, M/F (\%) & $31 / 22$ & - \\
Antihypertensive treatment & 29 & - \\
$\quad$ (\%) & & - \\
Laser therapy (\%) & 43 & - \\
Cataract extraction (\%) & 39 & - \\
Angina/MI (\%) & 34 & 64 \\
Smoking ever (\%) & 86 & \\
Alcohol (any) (\%) & & \\
\hline
\end{tabular}

Data are presented as means unless stated otherwise

$F$ female, $M$ male, $M I$ myocardial infarction

${ }^{\mathrm{a}}$ Mean
$43 \%$ reported laser therapy (though only $2 \%$ were blind), $39 \%$ had cataract surgery, and $34 \%$ reported angina or myocardial infarction [13]. Delayers had background retinopathy or albuminuria, and up to a third reported no complications at all. These were, however, self-reported data, and the number of true escapers is likely to be lower than this. The greatest escape was that of the medal winner who was able to come off insulin after 50 years of unnecessary therapy [16]!

Survivors of diabetes, as we have seen, are heterogeneous. Some appear unaffected by their disease, others bear the scars of their by-pass graft or renal transplant, and a few walking wounded carry a white stick or suffer with disabling neuropathy. The great majority lead an active and useful life [17]. The vascular complications of diabetes can progress at different rates, arbitrarily devastating one tissue yet sparing another, and even those whose vascular endothelium is unscathed may, nonetheless, have to endure neuropathy or cataract surgery. Despite so much diversity, these veterans have come through a rigorous selection process, and the features they share testify to the dangers they have managed to evade. Let us therefore pause to examine the bottleneck through which they have passed and to consider possible reasons for their success.

\section{The Bottleneck}

The Steno and Joslin experience tells us, with remarkable consistency, that about $40 \%$ of young people diagnosed before World War II survived 40 years of diabetes. Consistent with the other studies mentioned above, they found that about half of survivors have major complications, whereas the remainder are delayers or escapers. Up to $50 \%$ will have required laser therapy, a third will have microalbuminuria or proteinuria, and a few will have uraemia. A third will have overt coronary artery disease. Late complications cluster within individuals, but data on long-term diabetes have not been presented in such a way as to make this analysis possible, informative though it would be.

The question of key importance for our future understanding of diabetes concerns the distribution of risk within the type 1 population. There are two possible interpretations. The first is that the risk of late complications is continuous, albeit skewed, and that long-term survivors represent the tail of that distribution. Alternatively, it has been argued that there could be two or more subpopulations within the type 1 population, differing in susceptibility to diabetic nephropathy and associated coronary artery disease [18]. A bimodal distribution would imply major differences in genetic susceptibility to nephropathy or vascular 
disease, whereas a continuous distribution would suggest a leading role for glycaemia and its associated pathophysiological changes.

There are difficulties with either interpretation, and a more plausible model would combine metabolic exposure with a gradient (or multiple subpopulations) of genetic susceptibility; the interplay would determine both the risk of transition from 'background' to aggressive microvascular disease, and the rate at which this transition occurs. Glucose exposure would play the critical role in the early years of disease, whereas hypertension, lipids - and possibly insulin resistance [19] - will, in time, take over as the major determinants of outcome. I shall argue that the heterogeneous nature of the survivor population suggests that they are moving through the same pathological sequence, but on a slower track - in some cases slower than a lifetime. From a clinical point of view, the important question is whether, or to what extent, current therapy can switch an individual from the fast to the slow track, and these considerations are explored in the following sections.

\section{Nephropathy: the Scylla of Diabetes}

Nephropathy generally manifests within 15-25 years of disease onset, and is responsible for the greatest excess mortality in the young [20]. As a junior doctor, I once had to look after a 34-year-old man who was left in a hospital room to die of uraemia, no haemodialysis facilities being available. Mercifully, the prognosis of diabetic nephropathy has been transformed since then, and developments at the primary, secondary and tertiary levels of intervention have been responsible. At the primary level, the proportion of children and young adults developing proteinuria within 20-25 years of diagnosis has dropped from about $30 \%$ to about $10 \%$ within the past two decades, at least in studies from centres of excellence in Scandinavia [21, 22], and improved glucose control and ACE inhibitors for microalbuminuria are likely to have contributed to this. It must, however, be emphasised that these optimistic findings have yet to be replicated elsewhere [1]. At the secondary level, early aggressive anti-hypertensive therapy has extended the interval between the onset of proteinuria and renal replacement therapy [23]. Last but not least, the management of those in end-stage renal failure has improved beyond recognition. The collective effect has been to delay-and sometimes possibly to prevent - the onset of proteinuria, and to extend the mean interval between persistent proteinuria and death from 7 [20] to more than 21 years [24].

It is part of the folklore of the diabetic clinic that those who survive for 25 years or more without proteinuria are in some way immune to nephropathy. This is untrue. An early study showed that the annual incidence of nephropathy peaked at $2.4 \%$ in women and $3.4 \%$ in men after 16 years of diabetes, but that nearly a third of new cases occurred after 25 years; even after 40 years of diabetes the annual rate was $0.6 \%$ in women and $1.6 \%$ in men [20]. Nor could proteinuria ever be considered benign, for its mortality was $100 \%$ by 24 years, and uraemia developed to an equal extent in those who died before or after 10 years of proteinuria [20]. Furthermore, the bell-shaped pattern of incidence reported from Denmark [20] may not be universal, and the Pittsburgh Study showed a sustained increase in the incidence of nephropathy over the first 35 years of diabetes [25].

What may we conclude from the presence of microalbuminuria or proteinuria in up to a third of those in the Golden Years cohort [13]? A study in individuals with more than 30 years of type 1 diabetes found that those with microalbuminuria had lower glomerular filtration rates and higher serum creatinine levels than those with normal albumin excretion [26], and concluded that microalbuminuria cannot be considered benign at any stage of diabetes, as was once proposed [27]. The renal consequences of lateonset nephropathy may have been masked by coronary artery disease, and further studies are certainly needed to clarify this situation. In summary, long-term diabetes does not confer immunity to nephropathy and, when present, this cannot be assumed to be benign. This interpretation would favour a continuum of risk, modulated by overlapping genetic subpopulations. If this interpretation is correct, we may need to reconsider the widespread clinical assumption that improved glucose control and antihypertensive therapy have converted the malignant angiopathy of early-onset diabetes into something more benign. They may simply have shifted the survival curve to the right, as suggested by at least one study [25].

\section{Charybdis: Coronary Artery Disease}

Coronary artery disease is greatly accelerated in those with nephropathy $[25,28]$, to the extent that the excess coronary risk associated with type 1 diabetes is much reduced, although still well above baseline, when nephropathy is absent [29]. Long-term survivors are typically lean and normotensive, with raised HDL-cholesterol and relatively low insulin requirements, implying sensitivity to its actions (Table 1). Longitudinal data from the Steno Memorial Hospital showed a mean blood pressure of $135 / 70 \mathrm{mmHg}$ after 40 years or more of diabetes, as against $105 / 65 \mathrm{mmHg}$ when first examined, while BMI was unchanged at $22.4 \mathrm{~kg} / \mathrm{m}^{2}$ and the insulin dose had fallen to $0.49 \mathrm{U} / \mathrm{kg}[11,12]$.

Long-term survivors, as all this might suggest, are the antithesis of the metabolic syndrome [13], and this is consistent with the observation that survival in type 1 
diabetes is inversely related to insulin resistance [30]. It also complements the Third National Health and Nutrition Examination Survey (NHANES III), which found that individuals over the age of 50 with (mainly) type 2 diabetes but no features of the metabolic syndrome had a coronary heart disease prevalence of $7.5 \%$, compared with $13.9 \%$ for those who had the metabolic syndrome without diabetes, $19.2 \%$ for those who had both, and $8.7 \%$ for those who had neither diabetes nor the metabolic syndrome. Diabetes alone was not a risk factor for coronary heart disease in this study [31]. Observations such as these support the current view that isolated hyperglycaemia is a weak predictor of coronary disease, although perhaps relatively prominent in those who have escaped diabetic nephropathy [32].

The distribution of HDL-cholesterol in this population is of particular interest because it deviates so widely from that of non-diabetic controls. Neither the Joslin Study nor Golden Years reported HDL-cholesterol by sex, but the combined mean levels $(1.75$ and $1.84 \mathrm{mmol} / \mathrm{l}$, respectively) exceed the 90th centile for men and the 75 th centile for women in age-matched US adults [33], while $66 \%$ of those in the UK study had levels above the reference range $(0.6-1.6 \mathrm{mmol} / \mathrm{l})$ used by their laboratory [13]. HDL-cholesterol is $\sim 0.26 \mathrm{mmol} / 1$ higher in individuals with type 1 diabetes than in the rest of the population [32] but, even when corrected for this, the deviation suggests strong selection pressure upon the cohort.

\section{What Makes a Survivor?}

The likely major determinants are metabolic control, destiny and character. Other determinants of survival include age at onset of diabetes, for someone diagnosed at age 30 is less likely to live 50 years than someone diagnosed at age 10, and population-specific risk factors, such as the background prevalence of coronary artery disease, also need to be taken into account. For present purposes, however, we will focus on the first three.

Good glucose control prevents (or delays) both microangiopathy and macroangiopathy if instituted early in the course of diabetes, and the DCCT and the UK Prospective Diabetes Study (UKPDS) each demonstrated that these benefits persist beyond the period of intensified control [34, 35]. This 'legacy effect' is fashionably explained in terms of long-term programming or tissue memory, but those who detect a hint of necromancy in this proposition will note that simpler explanations are available, for the response of the vascular endothelium to glucose control may diminish over time, possibly in parallel with the accumulation of harmful changes, and cumulative glucose exposure still differs between the study groups.

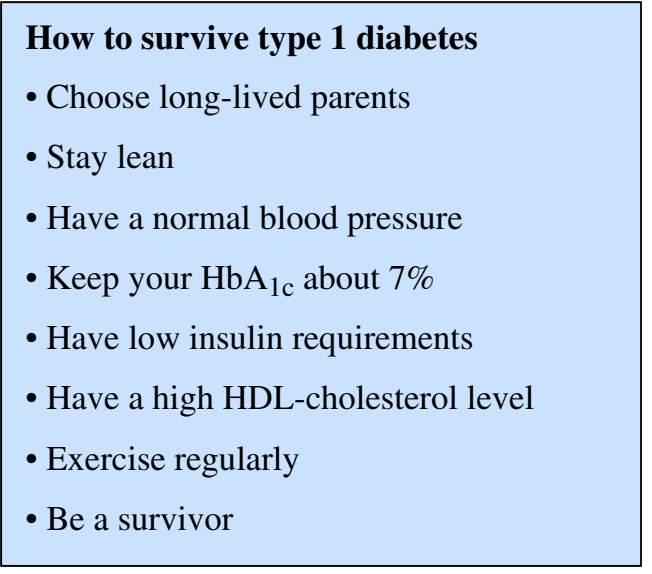

Cumulative glucose exposure was examined in the Early Diabetes Complications (EDC) cohort, in a study that introduced the concept of the $\mathrm{HbA}_{1 c}$-year [36]. This provides a cumulative measure of exposure to hyperglycaemia, analogous with the pack-year used to measure cigarette consumption. An $\mathrm{HbA}_{1 \mathrm{c}}$-year is derived by averaging $\mathrm{HbA}_{1 \mathrm{c}}$ values for each year of diabetes, and subtracting the value for the upper limit of the non-diabetic range. Thus, for example, a year in which DCCT-aligned $\mathrm{HbA}_{1 \mathrm{c}}$ averaged $8.1 \%$ would be equivalent to $2 \mathrm{HbA}_{1 \mathrm{c}}{ }^{-}$ years. The analysis suggested that about $1,000 \mathrm{HbA}_{1 \mathrm{c}^{-}}$ months were needed for any given complication of diabetes to develop, with the comforting corollary that those who maintain an $\mathrm{HbA}_{1 \mathrm{c}}$ of $7 \%$ will have nothing to worry about for 83 years. Needless to say, this seems rather too good to be true, and we risk the fate of the statistician who drowned in a river whose average depth was $1 \mathrm{~m}$. The authors readily acknowledge that their approach is limited by considerable inter-individual variation, and that non-linear consequences may emerge from continuous exposure to glucose and other metabolic risk factors [36].

Studies of long-term survivors have provided conflicting messages as to whether these have better than average control. Accurate estimates of glucose control cannot be derived over a 50 year period, but it is notable that the mean $\mathrm{HbA}_{1 \mathrm{c}}$ of the Joslin 50 year medal winners was 7.0\% at the time they were studied [14]. The UK medalists tell a different story, for they were tested with a non-DCCT aligned assay with a normal range of 3.5-5.0\%, and their reported mean $\mathrm{HbA}_{1 \mathrm{c}}$ of $7.6 \%$ should therefore be adjusted upwards by about $1 \%$, indicating rather average control [13]. Selection bias might explain the difference, for Joslin medalists are invited to self-nominate [8], which might attract the diabetes enthusiasts, whereas UK medalists are generally nominated by their physicians. Endogenous insulin secretion may persist in long-term diabetes, but only $2 \%$ of long-term survivors in the Steno cohort had postprandial C-peptide levels $>0.1 \mathrm{nmol} / 1$ [12], so this is 
unlikely to be an important influence. We can, in summary, be reasonably sure that good glucose control promotes prolonged survival in diabetes, especially (as the DCCT would suggest) if achieved early in the course of the disease [37], but other factors must also be considered.

\section{Destiny}

The suggestion that nephropathy is confined to a susceptible subset of the diabetic population was supported by the observation that it clusters within affected relatives [38]. This prompted a major hunt for diabetic nephropathy genes. Genes have, indeed, been identified [39], although many of the studies have been underpowered, but the ongoing search has not identified major monogenic determinants, and seems unlikely to do so. The familial component does, however, demonstrate strong heritability for diabetic nephropathy, and it can be noted that coronary heart disease [40] and longevity [41] also cluster within families. Longterm diabetes is associated with parental longevity; the Joslin study, for example, reported that fathers died at a mean age of 73.6 years and mothers at 78.4 years, as against the life table estimate of 47.6 years for those of either sex born in 1900 [14].

Familial clustering implies genetics, although we inherit more from our parents than their genes. HDL-cholesteroltypically raised both in centenarians [42] and long-term survivors of diabetes - is an example of a geneticallyinfluenced marker that offers an evident biological advantage. There must be others. A search for additional protective factors in survivors might therefore help to identify mechanisms underlying microvascular or macrovascular complications, and could point to possible therapies.

\section{Character}

Joslin believed there were four determinants of long survival with diabetes. The first was the general physical condition of the patient. The second was his or her disposition, intelligence, 'savoir faire', willingness and opportunity to follow the prescribed treatment. Third came regulation of diabetes, as shown by blood or urine glucose and weight control. Last of all, the outcome depended upon the willingness of their physician to provide 'the best treatment which modern medicine affords' [2]. Joslin had personal knowledge of every one of the first 98 Quarter Century Victory Medalists, and commented that 'those who received this medal were usually those who had ample resources and care in the early years of their disease, usually good homes, were intelligent and had the backbone to adhere to the rules of the disease' [7]. As the comment about 'backbone' might suggest, Joslin saw the quest to survive diabetes as a moral crusade, and made free use of concepts such as self-discipline, which have long since fallen out of fashion. As for those who could not meet his high standards (some of whom must surely have fled to other physicians), the best he could say for them was that they were 'careless'. 'No-one yet', as he said of his Victory Medal, 'has ever fulfilled the criteria for this award who has been careless in the management of his diabetes. Especially vigorous control of the disease in its earliest months and years has been essential' [7].

Sad to relate, we have since then made little progress in understanding the human determinants of long-term survival with diabetes, and the social, behavioural or psychological basis of long-term diabetes has not been studied, despite the central role of self-management in achieving this outcome. The role of traditional risk factors, such as low socioeconomic status, lack of education, being unmarried, smoking, alcohol and physical inactivity, has been extensively investigated in other chronic diseases but surprisingly little is known about their impact on diabetes. Studies such as these are sorely needed. Some anecdotal comments may, however, be ventured in their absence. Anyone who comes in contact with long-term survivors of diabetes will probably agree that these are self-directed people with a lot more than diabetes to live for. All have been reasonably careful in managing their diabetes, many have been meticulous, and some have been obsessional. Regular clinic attendance is a common feature, but this may tell us more about their attitude to their condition (or their chances of being ascertained) than about the quality of the care they have received. Others, disillusioned by their experience of health professionals, have opted to take on full responsibility for their own diabetes [43]. The resulting style of management, always idiosyncratic and sometimes bizarre, often works better than orthodox approaches to diabetes might lead us to believe, suggesting that it may be more important for people to make their own rules and follow them than to be familiar with the latest consensus algorithm. As for socioeconomic status, Joslin's remarks suggest that many of his long-term survivors came from a well-to-do or educated background. This group is probably over-represented in long-term diabetes, but my own veterans come from all walks of life. Character, in this respect at least, does seem to be more important than fortune.

\section{As Old as Your Arteries}

Joslin saw diabetes as a disease of accelerated ageing, and remarked that the biological age of a patient with diabetes should be taken as the chronological age plus 10 years. Two recent studies show that he was right. The first of these 
found that diabetes is the cardiovascular risk equivalent to 15 added years of age [44], and the second, restricted to type 1 diabetes, estimated 10-15 added years; the effect was only seen over the age of 40 [45]. It is, indeed, a matter of common observation that we age at different rates, and the same applies to our internal organs. People are judged to have aged successfully when everything falls apart in parallel and the brain holds out to the end. Conversely, the greatest threat to the elderly comes from premature or catastrophic failure of one of the functional networks upon which survival depends. Diabetes and atherosclerosis are not inevitable features of the ageing process, but the distinction between normal ageing and pathology easily becomes blurred. Senescence and diabetes go hand in hand and require joint consideration. The beta cell failure of type 2 diabetes is superimposed upon an age-related decline in beta cell function, and may, to some extent, represent the fast track of a ubiquitous process. With respect to arterial disease, a recent review has commented that 'cardiologists and most physicians believe that aging is an independent risk factor for human atherosclerosis, whereas atherosclerosis is thought to be a characteristic feature of aging in humans by many gerontologists', and continues that 'it may be more important to answer the question of how we age than what specifically promotes atherosclerosis' [46].

Several candidate mechanisms link age to vascular disease, and the telomere hypothesis is the best known of these [47]. Telomeres are DNA-protein complexes located at the end of chromosomes that serve as protective caps and shorten with each cell cycle. They function in much the same way as the strip purchased by travelers on the Copenhagen rail network - a punch machine removes the far end of the strip with each journey until your time is up. Telomere shortening is thought to act as a mitotic clock, and explains the limited replicative ability of cells in culture, otherwise known as the Hayflick limit [48]. Cells age more rapidly in response to inflammation and oxidative stress, and shortened telomeres are strongly associated with arterial disease. The Cardiovascular Health Study estimated that the risk of myocardial infarction or stroke was increased threefold for each kilobase pair reduction in terminal restriction fragment length [49]. Telomere attrition has been reported in both type 1 [50] and type 2 diabetes [51], and the overlap between the determinants of longevity and those of long-term diabetes suggests that this might be a fruitful area for future research.

\section{Back on the Farm}

It must surely be symptomatic of the way in which we conduct research that our entire clinical enterprise is mobilised to improve the survival of people with diabetes, yet we have scarcely bothered to study the survivors. Medal winners, instructive though they may be, are highly selected, and we know little about those who have not come forward. Nor can we be sure how many of those diagnosed 50 years ago have survived, although, as noted above, their deviation from the rest of the population in terms of HDL-cholesterol suggests an intense selection pressure. We have reason to believe that survival reflects more than metabolic control, important though this undoubtedly is, but we have little insight into the genetic background to survival and the mechanisms by which susceptibility or protection are mediated. We have yet to establish the impact of modern therapy upon the longer term outcome of type 1 diabetes. Last but not least, we know practically nothing about the social background, character and personal coping strategies of people who survive diabetes over long periods of time.

The prospect for those with childhood diabetes has improved, is improving, and (barring political or economic catastrophe) will continue to improve. Each child we start on insulin should reasonably expect to survive diabetes for more than 50 years. We (or our successors) may even see the existing gap in life expectancy between affected children and their peers begin to close, on the assumption that their peers will by then have encountered some genetic or constitutional limit to human longevity [48]. Others believe that the linear increase in life expectancy will continue [52], in which case the child with diabetes will always lag behind. Sadly, and in either event, the gap is unlikely to narrow much within my lifetime, and for reasons that are largely avoidable. Joslin did not know how to prevent or treat the retinal, renal and cardiovascular complications of diabetes. We do. Joslin overestimated the prognosis of children with diabetes. We must not. Children in the 'bottom billion' of the world's population still die for lack of insulin [53], and children in the developed world still die because we have the knowledge, but not the ability, to help them. As for ourselves, we are afflicted by the tunnel vision of all professionals. The prime function of an expert, as I have said elsewhere, is to define a problem in such a way that he (or, as it might be, she) emerges as the solution. Is this why we have chosen to ignore the overwhelming influence of social and psychological forces upon the outcome of diabetes? It is so much more comforting to believe that every positive outcome can be credited to our own therapeutic intervention.

As I drove away from Raymond's farm in a car laden with the vegetables he had grown, I remembered the story of the ancient Greek who became an atheist [54]. He was taken to a temple to see the grateful inscriptions left by those who had called upon the gods in moments of peril upon the sea, and had been saved. Yes, said the sceptic, but 
where are the messages from those who said their prayers and drowned?

Acknowledgements I thank Knut Borch-Johnsen, Helen Colhoun and Andrzej Krolewski for their helpful critique of this manuscript.

Duality of interest The author declares that there is no duality of interest associated with this manuscript.

\section{References}

1. Gale EAM (2005) Type 1 diabetes in the young: the harvest of sorrow goes on. Diabetologia 48:1435-1438

2. Joslin EP (1940) Chapters VIII and IX. In: Joslin EP, Root HF, White P, Marble A (eds) The treatment of diabetes mellitus, 7th edn. Lea and Febiger, Philadelphia

3. Krolewski AS, Warram JH, Christlieb AR (1985) Onset, course, complications and prognosis of diabetes mellitus. In: Marble A, Krall LP, Bradley RF, Christlieb R, Soeldner JS (eds) Joslin's diabetes mellitus, 12th edn. Lea and Febiger, Philadelphia, pp 251-277

4. Dublin LI (1951) The facts of life from birth to death. Macmillan, New York

5. Krolewski AS, Warram JH (2001) Natural history of diabetes mellitus. In: Becker KL (ed) Principles and practice of endocrinology and metabolism. Lippincott, Williams and Wilkins, Philadelphia, pp 1320-1327

6. Hagedorn HC (1959) Cases of diabetes of long duration. N Engl J Med 261:442-443

7. Ryan JR, Balodimos MC, Chazan BI et al (1970) Quarter century victory medal for diabetes: a follow-up of patients one to 20 years later. Metabolism 19:493-501

8. http://www.joslin.org/Files/Medalist2006Packet.pdf, accessed 20 January 2009

9. Cochran HA, Marble A, Galloway JA (1979) Factors in the survival of patients with insulin-requiring diabetes for 50 years. Diabetes Care 2:363-368

10. Oakley WG, Pyke DA, Tattersall RB, Watkins PJ (1974) Longterm diabetes. A clinical study of 92 patients after 40 years. Q J Med 43:145-156

11. Borch-Johnsen K, Nissen H, Henriksen E et al (1987) The natural history of insulin-dependent diabetes in Denmark: 1. Long term survival with and without late diabetic complications. Diabetic Medicine 4:201-210

12. Borch-Johnsen K, Nissen H, Henriksen E, Kreiner S, Salling N, Deckert T, Nerup J (1987) The natural history of insulindependent diabetes in Denmark: 2. Long-term survival-who and why. Diabetic Medicine 4:211-216

13. Bain SC et al (2003) Characteristics of Type 1 diabetes of over 50 years duration (the Golden Years Cohort). Diabetic Medicine 20:808-811

14. Keenan HA et al (2007) Clinical factors associated with resistance to microvascular complications in diabetic patients of extreme disease duration. The 50-year Medalist Study. Diabetes Care 30: 1995-1997

15. Evert J, Lawler E, Bogan H, Perls S (2003) Morbidity profiles of centenarians: survivors, delayers and escapers. J Gerontol A Biol Sci Med Sci 58:232-237

16. Armitage M, Frier BM, Duncan LJP (1983) A misplaced medal? 50 years of unnecessary insulin treatment. BMJ 286:844
17. Altman J-J, Vincent-Cassy C, Feldman-Billard S (2009) Improvements in the lifestyle of patients who have had type 1 diabetes for 50 years: an optimistic message. Diabetologia 52:364-366

18. Hougaard P, Myglegaard P, Borch-Johnsen K (1994) Heterogeneity models of disease susceptibility with application to diabetic nephropathy. Biometrics 50:1178-1188

19. Kilpatrick ES, Rigby AS, Atkin SL (2007) Insulin resistance, the metabolic syndrome, and complication risk in type 1 diabetes: "double diabetes" in the Diabetes Control and Complications Trial. Diabetes Care 30:707-712

20. Andersen AR, Sandahl Christiansen J, Andersen JK, Kreiner S, Deckert T (1983) Diabetic nephropathy in type 1 (insulindependent) diabetes: an epidemiological study. Diabetologia 25:496-501

21. Nordwall M, Bojestig M, Arnquist HJ, Ludvigsson J (2004) Declining incidence of severe retinopathy and persisting decrease of nephropathy in an unselected population with type 1 diabetesthe Linköping Diabetes Complications Study. Diabetologia 47:1266-1272

22. Rossing P (2005) The changing epidemiology of diabetic microangiopathy in type 1 diabetes. Diabetologia 48:1439-1444

23. Parving H-H, Anderson AR, Smidt UM, Svendsen PA (1983) Early aggressive antihypertensive treatment reduces rate of decline in kidney function in diabetic nephropathy. Lancet i: $1175-1179$

24. Astrup AS, Tarnow L, Rossing P, Pietraszek L, Riis Hansen P, Parving H-H (2005) Improved prognosis in type 1 diabetic patients with nephropathy: a prospective follow-up study. Kidney Int 68:1250-1257

25. Pambianco G, Costacou T, Ellis D, Becker DJ, Klein R, Orchard TJ (2006) The 30-year natural history of type 1 diabetes complications. The Pittsburgh Epidemiology of Diabetes Study experience. Diabetes 55:1463-1469

26. Mackin P, New JP, Macleod JM, Marshall SM (1996) Renal function in long-duration type 1 diabetes. Diabetes Care 19:249 251

27. Forsblom CM, Groop P-H, Ekstrand A, Groop LC (1992) Predictive value of microalbuminuria in patients with insulindependent diabetes of long duration. BMJ 305:1051-1053

28. Jensen T, Borch-Johnsen K, Deckert T (1987) Coronary heart disease in young type 1 (insulin-dependent) diabetic patients with diabetic nephropathy: incidence and risk factors. Diabetologia 30:144-148

29. Borch-Johnsen K, Andersen PK, Deckert T (1985) The effect of proteinuria on relative mortality in type 1 (insulin-dependent) diabetes. Diabetologia 28:590-596

30. Orchard TJ, Forrest KY, Olson JC et al (2003) Insulin-resistancerelated factors, but not glycemia, predict coronary artery disease in type 1 diabetes. Diabetes Care 26:1374-1379

31. Alexander CM, Landsman PB, Teutsch SM, Haffner SM (2003) NCEP-defined metabolic syndrome, diabetes, and prevalence of coronary heart disease among NHANES III participants age 50 years and older. Diabetes 52:1210-1214

32. Orchard TJ, Kretowski A, Costacou T, Nesto RW (2006) Type 1 diabetes and coronary artery disease. Diabetes Care 29:2528 2538

33. Adult Treatment Panel III (2002) Third Report of the National Cholesterol Education Panel (NCEP) Expert Panel on Detection, Evaluation and Treatment of High Blood Cholesterol in Adults (Adult Treatment Panel III) final report. Circulation 106:31433421

34. The Diabetes Control and Complications Trial/Epidemiology of Diabetes Interventions and Complications Research Group (2000) Retinopathy and nephropathy in patients with type 1 diabetes four years after a trial of intensive therapy. N Engl J Med 342:381-389 
35. Holman RR, Paul SK, Bethel MA, Matthews DR, Neil HA (2008) 10-year follow-up of intensive glucose control in type 2 diabetes. N Engl J Med 359:1577-1589

36. Orchard TJ, Forrest KY, Ellis D, Becker DJ (1997) Cumulative glucose exposure and microvascular complications in insulindependent diabetes mellitus. The glycemic threshold revisited. Arch Intern Med 157:1851-1856

37. The Epidemiology of Diabetes Interventions and Complications (EDIC) Study (2003) Sustained effect of intensive treatment of type 1 diabetes mellitus on development and progression of diabetic nephropathy. JAMA 290:2159-2167

38. Seaquist ER, Goetz FC, Rich S, Barbosa J (1989) Familial clustering of diabetic kidney disease. Evidence for genetic susceptibility to diabetic nephropathy. N Engl J Med 320:11611165

39. Freedman BI, Bostrom M, Daeihagh P, Bowden DW (2007) Genetic factors in diabetic nephropathy. Clin J Am Soc Nephrol 2:1306-1316

40. Brand FN, Kiely DK, Kannel WB, Myers RH (1992) Family patterns of coronary heart disease mortality: the Framingham longevity study. J Clin Epidemiol 45:169-174

41. Beeton M, Pearson K (1899) Data for the problem of evolution in man. II. A first study of the inheritance of longevity and the selective death rate in man. Proc R Soc Lond 65:290-305

42. Barzilai N, Gabriely I, Gabriely M, Iankowitz N, Sorkin JD (2001) Offspring of centenarians have a favorable lipid profile. J Am Geriatr Soc 49:76-79

43. Gill G, Jones K, Smyth C, Bain S, Barnett A (2003) Memories of the early years of insulin treatment in the UK. Practical Diabetes 20:103-107
44. Booth GL, Kapral MK, Fung K, Tu JV (2006) Relation between age and cardiovascular disease in men and women with diabetes compared with non-diabetic people: a population-based retrospective cohort study. Lancet 368:29-36

45. Soedamah-Muthu SS, Fuller JH, Mulnier HE, Raleigh VS, Lawrenson RA, Solhoun HM (2006) High risk of cardiovascular disease in patients with type 1 diabetes in the U.K.: a cohort study using the general practice research database. Diabetes Care 29:798-804

46. Minamino T, Komuro I (2008) Vascular cell senescence. Contribution to atherosclerosis. Circ Res 100:15-26

47. Samani NJ, van der Harst $P$ (2008) Biological ageing and cardiovascular disease. Heart 94:537-539

48. Hayflick L (1994) How and why we age. Ballantine, New York

49. Fitzpatrick AL, Kronmal RA, Gardener JP et al (2007) Leukocyte telomere length and cardiovascular disease in the Cardiovascular Health Study. Am J Epidemiol 165:14-21

50. Jeanclos E, Krolewski A, Skurnick J, Kimura M, Aviv H, Warram JH (1998) Shortened telomere length in white blood cells of patients with IDDM. Diabetes 47:482-486

51. Sampson MJ, Dozio N, Winterborn S, Hughes DA, Hughes JC (2006) Monocyte telomere shortening and oxidative DNA damage in type 2 diabetes. Diabetes Care 29:283-289

52. Oeppen J, Vaupel JW (2002) Broken limits to life expectancy. Science 296:1029-1031

53. Gale EAM (2006) Dying of diabetes. Lancet 368:1626-1628

54. Montaigne $\mathrm{M}$ de (1603) Of prognostications. In: The Essayes of Michel Lord of Montaigne (trans. Florio J, Sims V). Blount, London (reprinted in Everyman's Library, Dutton, New York, 1910) 